\title{
O PAPEL DA UNIVERSIDADE EM INICIATIVAS VOLTADAS À INFORMAÇÃO, CIDADANIA E ACCOUNTABILITYEM CÓRDOBA E SÃO PAULO
}

\author{
THE ROLE OF THE UNIVERSITY IN INITIATIVES AIMED AT INFORMATION, CITIZENSHIP AND ACCOUNTABILITY IN \\ CORDOBA AND SÃO PAULO
}

\section{EL PAPEL DE LA UNIVERSIDAD EN LAS INICIATIVAS DESTINADAS A LA INFORMACIÓN, LA CIUDADANÍA Y LA RENDICIÓN DE CUENTAS EN CÓRDOBA Y SAO PAULO}

\section{Resumo}

Este trabalho tem por objetivo identificar os diferentes papéis que a universidade pode desempenhar quando se envolve em iniciativas da sociedade civil voltadas a informação, cidadania e accountability social em cidades latino-americanas, particularmente nas iniciativas da Rede Nossa São Paulo e da Red Ciudadana Nuestra Córdoba. 0 contexto do trabalho leva em consideração os desafios contemporâneos nas cidades latino-americanas, os possíveis papéis da universidade diante deles e a diferença de atuação das universidades nas duas iniciativas estudadas, as quais fazem parte da Rede Latino-Americana por Cidades e Territórios Justos, Democráticos e Sustentáveis. Com base em pesquisa exploratória e descritiva, realizada em 2015, em Córdoba e São Paulo, identificam-se os diferentes papéis, as razões que os explicam e os efeitos da interação entre universidade e iniciativas na atuação de ambas e nas suas cidades.

Palavras-chave: Relação universidade-sociedade, cidadania, informação, Rede Nossa São Paulo, Red Ciudadana Nuestra Córdoba.

Camila Pagani - pagani.camila@gmail.com

Mestre em Administração pela Universidade do Estado de Santa Catarina, Centro de Ciências da Administração e Socioeconômicas Florianópolis - SC, Brasil

Paula Chies Schommer - paulacs3@gmail.com

Professora da Universidade do Estado de Santa Catarina, Centro de Ciências da Administração e Socioeconômicas - Florianópolis SC, Brasil

Submetido 26.07.2016. Aprovado 19.02.2017

DOI: http://dx.doi.org/10.12660/cgpc.v22n71.63434

\section{NOTA DE AGRADECIMENTO}

As autoras agradecem à Fundação de Amparo à Pesquisa e Inovação do Estado de Santa Catarina (FAPESC) e ao Conselho Nacional de Desenvolvimento Científico e Tecnológico (CNPq) pelo financiamento parcial ao projeto de pesquisa no âmbito do qual foi realizado o presente trabalho. 


\section{ABSTRACT}

The aim of this research is to identify different roles universities can perform when participating in civil society-led initiatives to promote information, citizenship and social accountability in Latin-American cities, especially the initiatives of Rede Nossa São Paulo and Red Ciudadana Nuestra Córdoba. The context for this work takes into consideration the challenges Latin American cities face nowadays, the potential roles of universities to deal with these challenges and the differences between the participation of universities in the two initiatives studied, both of which are members of the Latin American Network for Fair, Democratic and Sustainable Cities and Territories. Based on a descriptive and exploratory research conducted in 2015 in Córdoba and in São Paulo, this work identifies different roles, the motivation around them and the effects of the interaction between the university and the initiatives operating in the cities.

Keywords: relationship between university and society, citizenship, information, Rede Nossa São Paulo, Red Ciudadana Nuestra Córdoba.

\section{Resumen}

Este trabajo intenta identificar los diferentes papeles que la universidad puede desempeñar cuando se involucra con iniciativas de la sociedad civil destinadas a la información, ciudadanía y accountability social en ciudades latinoamericanas, particularmente, con las iniciativas de la Rede Nossa São Paulo y de la Red Ciudadana Nuestra Córdoba. El contexto del estudio considera los desafíos contemporáneos en las ciudades latinoamericanas, los posibles papeles de la universidad ante dichos desafíos y la diferencia de actuación de las universidades en las dos iniciativas estudiadas, las cuales forman parte de la Red Latinoamericana por Ciudades y Territorios Justos, Democráticos y Sustentables. Con base en la investigación exploratoria y descriptiva realizada en 2015, en Córdoba y São Paulo, se identifican los diferentes papeles, las razones que los explican y los efectos de la interacción entre la universidad y las iniciativas en la actuación de ambas y en sus ciudades.

Palabras clave: Relación universidad-sociedad, ciudadanía, información, Rede Nossa São Paulo, Red Ciudadana Nuestra Córdoba.

\section{INTRODUÇÃO}

Entre as características marcantes das cidades latino-americanas, estão a desigualdade social e as tensões decorrentes da fragmentação socioeconômica de seus territórios. A maior cidade brasileira, São Paulo, e a segunda maior cidade argentina, Córdoba, são expressões dessas características. São também cidades historicamente dinâmicas em termos culturais, econômicos e políticos. Lugares de intensa produção de conhecimentos e de inovações em cidadania e democracia, e endereço de universidades importantes em seus países.

Diante de desafios urbanos crescentes e de certo descrédito em relação às instituições políticas tradicionais, essas e outras cidades latino-americanas vivenciaram, nos últi- mos anos, a necessidade de promover iniciativas voltadas à qualificação e dinamização da participação cidadã. Um dos elementos-chave para isso seria a produção e sistematização de informações sobre a cidade, além da elaboração de propostas de soluções para esses desafios e do monitoramento de políticas públicas e de indicadores de qualidade de vida na cidade.

Diversas iniciativas nesse sentido, primeiramente em cidades colombianas e, a seguir, em outros países da região, originaram a Rede Latino-Americana por Cidades e Territórios Justos, Democráticos e Sustentáveis (RLCTJDS) (Cáceres, 2014; Dahmer, 2014). Hoje presente em 10 países e aproximadamente 70 cidades e territórios, envolvendo diversidade de segmentos da sociedade, trata-se de uma inovação democrática com 
potencial de incidência em instituições e políticas públicas no âmbito local, por meio da promoção do acesso à informação, da accountability social e da participação cidadã (Quinõnes \& Cuadros, 2014).

Para Quinõnes e Cuadros (2014), há um discurso compartilhado entre os atores da sociedade civil ligado a essa nova forma de expressão e representação política. Um discurso sobre democracia e sustentabilidade que prioriza aspectos políticos e instrumentais como transparência, acesso à informação, exigência de prestação de contas e incentivo a sanções sociais e culturais. Para Cáceres (2014), essas iniciativas colocam em evidência a valorização do acesso à informação, de modo a promover a transparência, a accountability pelos governos e a qualificação do processo de participação.

Accountability que, no contexto democráti$\mathrm{co}$, refere-se sobretudo à responsabilização política dos governantes em relação à sociedade (Abrucio \& Loureiro, 2005; O'Donnell, 1998). E é nesse sentido que muitas das iniciativas pertencentes à RLCTJDS trabalham. Elas visam aprimorar a dinâmica dos canais de participação e qualificar o processo político nas democracias locais (Cáceres, 2014). Ao enfatizar a participação cidadã no processo de accountability, tais iniciativas remetem ao conceito de accountability social. Para Gómez e Delgado (2011), "distanciando-se de um entendimento dominante que associa a accountability ao âmbito das instituições democráticas, adiciona-se o termo 'social' para se referir ao papel da ação coletiva de organizações da sociedade civil na ampliação e fortalecimento da democracia" (p. 5). No mesmo sentido, Jimenéz (2012) destaca que a accountability social pode ser compreendida como uma forma de fortalecimento da política, por permitir uma relação mais profunda entre governos, instituições, fundações, organismos multilaterais, cidadãos e meios de comunicação.

Uma vez que as iniciativas da RLCTJDS enfatizam a importância, por um lado, da informação e do conhecimento, e, por outro, da participação e da accountability social para agir sobre os desafios nas cidades, é razoável supor que a presença das universidades nelas seja relevante. Tanto por estas serem tradicionalmente reconhecidas por seu papel na produção de conhecimento, como pela expectativa contemporânea de que contribuam para a democratização do saber e para a solução de problemas públicos, por meio de atuação contextualizada, articulando, de maneira interdisciplinar, os saberes científicos a outros saberes presentes na sociedade.

Estudos sobre iniciativas que integram a RLCTJDS, como a Red Ciudadana Nuestra Córdoba (Cáceres, 2014; D'Amico, Martiarena, \& Peralta, 2013), a Rede Nossa São Paulo (Fiabane, Alves, \& Brelàz, 2014; Nascimento, 2015) e outras, em cidades da América Latina (Dahmer, 2014; Quinonez, 2011), permitem observar diferentes possibilidades e graus de intensidade na articulação entre as universidades e as iniciativas, as quais costumam contar, ainda, com a presença de pessoas e organizações ligadas ao meio empresarial, à mídia e a segmentos da sociedade civil e movimentos sociais diversos. Esses estudos já realizados sobre iniciativas no âmbito da RLCTJDS, embora sinalizem a presença e diferentes formas de participação das universidades, não exploram especificamente os papéis desempenhados por 
essas instituições nessas iniciativas, lacuna que se busca explorar no presente trabalho. No contexto latino-americano, especialmente a partir das revoluções sociais do século $\mathrm{XX}$ e com as lutas sociais e políticas desencadeadas a partir delas, a universidade passa a ser considerada uma "instituição social inseparável da ideia de democracia e de democratização do saber" (Chauí, 2003, p. 5), o que enfatiza sua atuação de maneira articulada a outras organizações. Nesse sentido, é razoável supor que, além de fatores culturais, políticos e institucionais que influenciam a universidade, como conjunto, em cada local e cada instituição, sua atuação e suas relações apresentem características particulares, possivelmente associadas a fatores históricos e de relação entre os atores sociais em cada contexto específico. Cabe, então, identificar e refletir sobre como a universidade pode influir e ser influenciada no desenvolvimento cultural, econômico e social da cidade a partir dos diferentes papéis que exerce nas relações com iniciativas da sociedade civil, em cada contexto.

Diante dos desafios contemporâneos nas cidades latino-americanas, dos possíveis papéis da universidade diante deles e da diferença de atuação das universidades em duas destacadas iniciativas da RLCTJDS, definiu-se, como objetivo deste trabalho, identificar os diferentes papéis que a universidade pode desempenhar quando se envolve em iniciativas da sociedade civil voltadas a informação, cidadania e accountability social em cidades latino-americanas, particularmente nas iniciativas da Rede Nossa São Paulo e da Red Ciudadana Nuestra Córdoba. Interessa observar os diferentes papéis, as razões que os explicam e os efeitos des- sa interação entre universidade e iniciativas na atuação de ambas e nas suas cidades.

A seguir, apresenta-se um panorama histórico-conceitual sobre a universidade como instituição e seus papéis na sociedade. $\mathrm{Na}$ sequência, descrevem-se os procedimentos metodológicos da pesquisa realizados em 2015 e as características básicas de cada caso. Posteriormente, analisa-se o papel das universidades nos dois casos, identificando-se razões e efeitos de sua atuação, concluindo-se com as considerações finais e referências.

Entre os principais achados da pesquisa, estão os diferentes papéis exercidos pelas universidades diante das iniciativas. Em ambos os casos, verificam-se (i) o apoio institucional e (ii) o aporte de metodologias e conhecimentos especializados, sendo esse apoio e esse aporte mais evidentes, contínuos e institucionalizados em Córdoba do que em São Paulo. Além disso, em Córdoba, há (iii) contribuição financeira das universidades e (iv) envolvimento direto e continuado de reitores, professores e estudantes das universidades no grupo coordenador e em atividades da rede. As razões que explicam as diferenças na relação entre universidades e iniciativas em cada cidade estão relacionadas (i) ao contexto histórico, político e institucional da cidade - genericamente: Córdoba, cidade universitária; São Paulo, cidade industrial - e (ii) às lideranças que atuaram na constituição da iniciativa - predominantemente acadêmicas em Córdoba; sobretudo empresariais, em São Paulo - e (iii) à visão das universidades quanto ao envolvimento em iniciativa voltada a informação, cidadania e accountability na cidade. 
Os efeitos da relação entre universidade e iniciativas da sociedade civil são identificados em três âmbitos, com diferenças entre as duas cidades: novos espaços institucionalizados de articulação de saberes e formas de produção de conhecimentos na cidade; mudanças em instituições tradicionais como a universidade; ampliação e reconfiguração de espaços institucionais de articulação entre governos e cidadãos.

\section{A UNIVERSIDADE E SEUS PAPÉIS}

Como instituição social, a universidade "exprime de maneira determinada a estrutura e o modo de funcionamento da sociedade como um todo" (Chauí, 2003, p. 5). Isso porque conta com a presença de opiniões, atitudes e projetos conflitantes que expressam divisões e contradições da sociedade.

A autonomia conferida às universidades não significa que sejam independentes do contexto em que se inserem. Pelo contrário, como instituição social, a universidade acompanha transformações sociais, econômicas e políticas (Bernheim \& Chauí, 2008), sendo influenciada e capaz de influenciar a agenda pública, na medida em que o conhecimento que produz alcança repercussão social.

No atual cenário global, particularmente na América Latina, a relação da universidade com a sociedade é desafiada. A formação de uma cidadania responsável e o fortalecimento da esfera pública constituem fatores decisivos na elaboração de pautas sociais e modelos de comprometimento da universidade.

De acordo com Santos (2011), a efetividade de seu papel social depende da capacidade da universidade de fazer com que o conhecimento produzido transpasse as paredes institucionais e torne-se transdisciplinar, contextualizado, socialmente responsável, permitindo o diálogo entre outros saberes existentes na sociedade. Essa capacidade levaria, na visão desse autor, à passagem do conhecimento universitário para o conhecimento pluriversitário.

O conhecimento universitário, segundo Santos (2011), refere-se a um conhecimento homogêneo e organizacionalmente hierárquico. Tal modelo de conhecimento, segundo esse autor, foi desestabilizado ao longo das últimas décadas, permitindo a emergência de um novo modelo de conhecimento, o pluriversitário.

Esse novo modelo refere-se a um conhecimento contextual, tendo em vista que seu princípio organizador é a aplicação que lhe pode ser dada. Os resultados dessa aplicação, para além das paredes institucionais, leva em conta a formulação de problemas, a determinação de sua relevância e as formas de resolução de maneira partilhada entre pesquisadores e usuários, ou seja, a sociedade. Como sugere o autor, trata-se de um conhecimento transdisciplinar que pressupõe o diálogo e o confronto entre outros tipos de conhecimento, levando em conta o contexto em que se insere (Santos, 2011).

Para Vallaeys (2004), é imprescindível desenvolver a visão sistêmica da realidade. Para tanto, faz-se necessário redesenhar a instituição universitária. "Es preciso 'desfragmentar' los saberes, que los estudiantes puedan trabajar más a partir de problemas interdisciplinarios como son los de 'Desar- 
rollo sostenible"' (Vallaeys, 2004 p. 3). Segundo este autor, é preciso deixar claro que qualquer especialidade que não colabore com outras não é mais que um "saber cego". Além da interdisciplinaridade, o saber científico é desafiado a articular-se com outros saberes. Dessa forma, Santos (2010) conceitua ecologia de saberes. Trata-se de uma "ideia pragmática de que é necessária uma reavaliação das intervenções e relações concretas na sociedade e na natureza que os diferentes conhecimentos proporcionam" (Santos, 2010, p. 60). O conhecimento não apenas representa a realidade, mas também intervém nela.

Segundo Delanty (2001), novos modos de produção de conhecimento não levam necessariamente a modelos culturais capazes de explorar o potencial democrático do conhecimento. Talvez esteja aí um papel primordial da universidade, o de contribuir para recuperar o espaço público de discussão, por meio da interconexão de saberes. Além disso, a universidade é uma instituição-chave para a formação da cidadania cultural e tecnológica (Delanty, 2001).

Por outro lado, essas instituições podem também transformar-se a partir do envolvimento com outras instituições ou iniciativas sociais. O contexto contemporâneo das cidades evidencia desafios às formas tradicionais de produção de conhecimento sobre as mesmas. Esses desafios podem influenciar a responsabilidade social da universidade e a institucionalização de programas ou projetos voltados às cidades $e$ territórios em que se inserem.

No âmbito da governança de cidades, particularmente na América Latina, os espaços e modos de relação entre governo e sociedade, de exercício de poder, de participação cidadã e de accountability social, vem se transformando a partir da emergência de iniciativas recentes da sociedade civil e da articulação de atores de maneira ativa. Tais iniciativas são reflexos da realidade e do contexto institucional em que se inserem e, ao mesmo tempo, ajudam a questionar, transformar e redefinir elementos desse contexto. Há, portanto, múltiplas oportunidades de relações entre universidade e outros atores da sociedade, assim como oportunidades de expansão de fronteiras e de construção de novos conhecimentos (Schommer \& Boullosa, 2010). Há, também, obstáculos resistências e fatores históricos que interferem nos tipos de relações estabelecidas e nos seus resultados.

Em síntese, o envolvimento das universidades em iniciativas da sociedade civil em cidades latino-americanas, especialmente aquelas voltadas à informação, cidadania e accountability social, pode gerar transformações sociais e institucionais, na medida em que potencializa a produção de conhecimento pluriversitário, interdisciplinar e contextualizado. Os diferentes papéis que podem desempenhar a partir desse envolvimento geram oportunidades para a própria universidade, para as iniciativas e para a cidade. O desempenho desses papéis e seus efeitos variam em intensidade e forma. Interessa, portanto, observar como ocorre essa interação em cidades específicas, quais os fatores que explicam as diferenças entre uma e outra, e quais os efeitos da interação entre universidade e iniciativas da sociedade civil na atuação de ambas. 


\section{ABORDAGEM METODOLÓGICA E CA- RACTERIZAÇÃO DAS INICIATIVAS ESTU- DADAS}

A presente pesquisa caracteriza-se como exploratória, descritiva e explicativa, de natureza qualitativa, uma vez que parte da observação dos fenômenos e hipóteses levantadas acerca dos diferentes papéis que podem ser exercidos pelas universidades em iniciativas da sociedade civil. Os dados obtidos foram categorizados em três grandes temas: papéis, razões e efeitos do envolvimento das universidades nessas iniciativas, usando recursos de análise comparativa de duas experiências que integram a RLCTJDS: a Red Ciudadana Nuestra Córdoba e a Rede Nossa São Paulo.

As experiências em estudo foram escolhidas com base em evidências prévias acerca do papel das universidades, especialmente no caso de Córdoba. Nesse caso, a universidade foi fundamental no surgimento e condução da Red Ciudadana Nuestra Córdoba. Esta, por sua vez, gerou efeitos sobre a universidade. Ademais, considerou-se importante fazer um paralelo com uma experiência no Brasil. Optou-se, então, pela experiência de maior destaque no País, a Rede Nossa São Paulo, inspiração para a experiência de Córdoba em diversos aspectos. Várias características foram passíveis de comparação entre os dois casos, que refletiram nos diferentes papéis desempenhados pelas universidades: características da cidade, lideranças envolvidas, objetivos etc. O estudo privilegiou a interpretação, pelos pesquisadores, da percepção dos atores sociais envolvidos, que, articulada a elementos do contexto histórico e sociopolítico de cada iniciativa, permitiu uma análise das relações interinstitucionais. Os meios para a obtenção de dados foram pesquisa bibliográfica, pesquisa documental, observação direta não participante e entrevistas semiestruturadas individuais.

Foram realizadas 18 entrevistas, no período de 7 a 17 de abril de 2015. Em Córdoba, foram 12 entrevistas e, em São Paulo, seis. Os atores pesquisados foram escolhidos com base em indicações de outros pesquisadores que já tinham envolvimento com as iniciativas estudadas. Optou-se por pessoas ligadas a diferentes instituições envolvidas, de diferentes segmentos, e com clara atuação nas iniciativas. Buscou-se entrevistar pessoas ligadas à universidade (reitores, professores e servidores), pessoas atuantes na organização da iniciativa (coordenadores, diretores executivos), integrantes da administração pública local (servidores das prefeituras, secretários), além de parceiros, como pessoas do meio empresarial e da mídia, como o Jornal La Voz del Interior, de Córdoba, diretamente envolvido e apoiador da iniciativa na cidade. As entrevistas efetivamente realizadas resultaram, também, de conveniência, no sentido do tempo disponível dos pesquisadores para trabalho de campo em cada cidade, e disponibilidade e interesse dos entrevistados para participar. Buscaram-se também, previamente, informações em instituições ligadas às iniciativas, a exemplo da Fundação Avina, que apoiou a articulação da RLCTJDS e possui um banco de dados sobre a mesma. Utilizaram-se, ainda, relatórios, reportagens e outras entrevistas realizadas e publicadas anteriormente como fonte de dados. Na fase exploratória, em que se delineou o trabalho de campo a ser realizado, também foram obtidas informações por meio de observa- 
ção direta não participante, por intermédio do acompanhamento de reuniões, fóruns de discussão e eventos organizados por participantes da RLCTJDS. Para o acompanhamento e observação, foram feitas anotações e registros de áudio por meio de gravações autorizadas pelos participantes para posterior transcrição das informações obtidas em todo o trabalho de campo.

Quanto aos dados secundários, foram coletados documentos produzidos em meios impresso e digital, como jornais, relatórios técnicos, institucionais e de gestão, folders, cartilhas, apresentações institucionais e vídeos. Esses materiais permitiram obter dados sobre o contexto e características das iniciativas estudadas. Além disso, foram utilizados livros, revistas, anais, teses, dissertações e artigos relativos às iniciativas pesquisadas e outras semelhantes.

\section{A Rede Nossa São Paulo}

Lançado em maio de 2007, o inicialmente denominado Movimento Nossa São Paulo, posteriormente Rede Nossa São Paulo, baseou-se na percepção da realidade da atividade política no Brasil, das instituições públicas e da democracia. Com base na constatação da falta de confiança pela população e da necessidade de promover valores associados ao desenvolvimento sustentável, à ética e à democracia participativa, o Movimento estruturou-se como expressão de uma ampla articulação entre diferentes segmentos sociais na cidade de São Paulo (Fiabane, Alves, \& Brelàz, 2014).

As primeiras ideias para criação de um movimento nesse sentido surgiram no final de 2006, quando conselheiros do Instituto
Ethos de Empresas e Responsabilidade Social, Oded Grajew, Mara Cardeal, Guilherme Leal e Ricardo Young, participavam, em Amsterdã, na Holanda, da Conferência Anual da Global Reporting Initiative (GRI) (Rede Nossa São Paulo [RNSP], 2015). Era o período pós-eleições presidenciais de 2006. O cenário era de frustração diante da falta de boas propostas, da pobreza do debate e da ausência da sustentabilidade da agenda política eleitoral. Percebia-se a necessidade de fazer algo para mobilizar a sociedade brasileira para a sustentabilidade, o que passava pela revalorização da política e poderia ter a cidade como ponto de partida (Rede Nossa São Paulo [RNSP], 2015). Nessa época, ganhava repercussão a experiência da cidade colombiana de Bogotá, que estava alcançando avanços importantes em cidadania e qualidade de vida, por meio de diversas iniciativas, entre elas o Bogotá Cómo Vamos (Rede Nossa São Paulo [RNSP], 2015). As metodologias utilizadas em Bogotá para demandar, produzir e debater dados e indicadores sobre a cidade e para mobilizar cidadãos e políticos em torno de seus desafios inspiraram o desenho e as estratégias do Movimento Nossa São Paulo. A Fundação Avina fomentou a ida dos conselheiros mencionados acima a Bogotá, visando conhecer de perto tal realidade. Também foram inspiradoras experiências brasileiras de processos participativos e de transparência, como as de Porto Alegre, bem como avanços em serviços públicos, como os Bus Rapid Transit (BRTs) de Curitiba, que também foram inspiração para Bogotá.

Além de São Paulo, outras cidades vinham se articulando no mesmo sentido, no Brasil e em outros países da América Latina, constituindo a Rede Social Brasileira por Cidades Justas e Sustentáveis e a RLCTJDS (Dah- 
mer, 2014; RNSP, 2015). A experiência de São Paulo constituiu, desde o princípio, referência importante para outras cidades, tanto pelo trabalho e visibilidade de suas lideranças como por sua complexidade e dimensão. A cidade concentra, em grande escala, problemas encontrados em outras cidades brasileiras e latino-americanas. Seus desafios, estratégias e êxitos serviriam como exemplo de transformações possíveis para outras cidades (RNSP, 2015).

A mudança do nome, de Movimento Nossa São Paulo para Rede Nossa São Paulo, deu-se em 2010, também influenciada por debates sobre nomenclatura no âmbito das Redes Brasileira e Latino-Americana. Segundo relatório da RNSP (2015), a ideia de rede definiria mais precisamente seu modo de trabalho, baseado em princípios de ação inclusiva, com decisões conjuntas e não hierarquizadas. Cada Grupo de Trabalho (GT), por exemplo, poderia tomar decisões por conta própria, sem consultar todos os integrantes e sem autorização da direção.

O propósito foi, portanto, o de constituir uma rede no âmbito da sociedade civil, autônoma e independente, aberta à participação de pessoas e instituições não partidárias que tivessem interesse de contribuir com os objetivos dos moradores da cidade, visando a um desenvolvimento mais justo e sustentável. O diálogo foi definido como uma de suas ferramentas mais importantes; a disponibilização aos governos de propostas concretas para os desafios da cidade, uma de suas principais estratégias (RNSP, 2015), algo que exigiria a sistematização, produção, análise e debate de informações qualificadas.
No que concerne à estrutura administrativa, os integrantes organizam-se em uma Secretaria Executiva, um Colegiado de Apoio, e Grupos e Intergrupos de Trabalho. A Secretaria Executiva tem um caráter administrativo, e foi criada para operacionalizar o movimento e contribuir na elaboração das suas propostas e ações, cuidar da comunicação, produção técnica e mobilização (RNSP, 2015). A Secretaria Executiva está formalizada na figura jurídica do Instituto São Paulo Sustentável (ISPS), como uma associação sem fins lucrativos que recebeu a qualificação de Organização da Sociedade Civil de Interesse Público (OSCIP).

Os GTs permitem a participação de pessoas e entidades que se interessam em contribuir com os objetivos da rede e contribuem com conhecimentos específicos de especialistas e organizações. Os GTs foram surgindo à medida que determinados assuntos tornaram-se estratégicos. Algumas áreas mereceram destaque e deram nome a GTs: Segurança, Assistência Social, Cultura, Educação, Meio Ambiente, Orçamento, Trabalho e Renda, Mobilidade Urbana, Criança e Adolescente, Democracia Participativa, Acompanhamento da Câmara, Indicadores, Saúde. Os GTs são constituídos por representantes de entidades e cidadãos, e cumprem uma agenda decidida coletivamente, incluindo reuniões periódicas. Os grupos têm autonomia para planejar as ações sob a perspectiva de cada área temática (Nascimento, 2015; RNSP, 2015). Entre os representantes, estão empresas, ONGs, universidades, lideranças locais etc.

O Inter-GTs, por sua vez, é o grupo que conta com a participação de vários GTs e foi criado para aumentar o grau de interação 
entre os participantes da rede (RNSP, 2015). Isso porque os temas, muitas vezes, estão interligados quando se fala em desenvolvimento sustentável.

O Colegiado de Apoio é uma espécie de conselho criado para ampliar as discussões mais estratégicas, para além do âmbito da Secretaria Executiva. É composto por lideranças que estavam mais envolvidas com $o$ movimento desde os seus primeiros passos. O Colegiado reúne-se mensalmente e é responsável pela coordenação geral da Rede Nossa São Paulo (Nascimento, 2015; RNSP, 2015).

Em 2015, mais de 700 organizações integravam a rede, que busca expandir-se de maneira horizontal. A iniciativa conta com o apoio de lideranças comunitárias, entida- des da sociedade civil, empresas e cidadãos interessados em participar. São diversos os objetivos, estratégias e modos de gestão, portanto as participações dos representantes variam de intensidade. Alguns atuam ativamente, ao passo que outros apresentam-se como apoiadores. O Gráfico 1, baseada em levantamento de Nascimento (2015), mostra a distribuição dos integrantes da Rede Nossa São Paulo, conforme classificação em empresas multinacionais $(7,8 \%)$, empresas locais $(26,1 \%)$, organizações da sociedade civil (OSCs) ligadas ao meio empresarial, como institutos e fundações empresariais (4\%), OSCs de base $(14,6 \%)$, OSCs profissionais $(27,2 \%)$, redes, fóruns e coletivos $(3,7 \%)$, universidades e centros de estudo $(8,4 \%)$, organizações de mídia $(2,4 \%)$, organizações internacionais $(1,4 \%)$, sindicatos $(1,9 \%)$ e movimentos sociais $(2,4 \%)$.

Gráfico 1. Distribuição dos integrantes da Rede Nossa São Paulo por setor

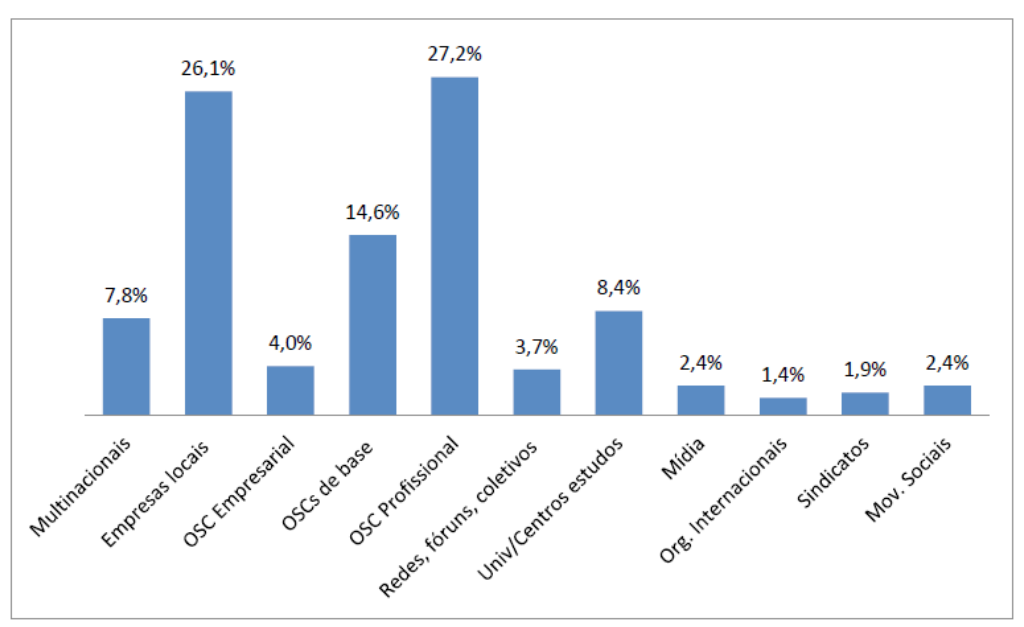

Fonte: Nascimento (2015), com base em dados da RNSP (2015). 
O PAPEL DA UNIVERSIDAdE EM INICIATIVAS VOLTADAS À INFORMAÇ̃̃o, CIDADANIA E ACCOUNTABILITY EM CÓRDOBA E SÃo PAULO

Os movimentos e associações possuem forte atuação na Rede Nossa São Paulo, contando com a participação efetiva de lideranças comunitárias locais. A mídia desempenha um papel fundamental para a Rede Nossa São Paulo, desde seu lançamento em 2007, divulgando artigos escritos por seus membros e entrevistas com lideranças em diversas rádios. O Ibope, maior empresa privada de pesquisa da América Latina, é outro importante parceiro na realização de pesquisas de diagnóstico e percepção da cidade, como os Indicadores de Referência de Bem-Estar no Município (Irbem), Dia Mundial Sem Carro e pesquisa de percepção "Viver em São Paulo" (Nascimento, 2015).

Desde a constituição da Rede Nossa São Paulo, percebeu-se a necessidade de capacidade técnica para produção de conhecimento, muitas vezes especializado, o que exigia a participação de pessoas e instituições que conhecessem os temas a serem abordados. Nesse sentido, recorreu-se a acadêmicos e pesquisadores ligados a universidades e centros de pesquisa, além de a empresas e pessoas especialistas em áreas específicas de atuação. Além de conhecimentos técnicos qualificados e especializados, também seria necessário utilizar novas tecnologias de informação, promover a educação cidadã e a mobilização social para aumentar a capacidade de pressão sobre os governos (RNSP, 2015).

Quanto a instituições universitárias e centros de estudo e pesquisa participantes da Rede Nossa São Paulo, somavam 26, em 2015. Muitas delas apenas como apoiadoras da iniciativa, sem atuação direta e contínua. Entre as que atuam diretamente, ainda que em projetos isolados ou por meio de algumas pessoas específicas, destacam-se a Universidade de São Paulo (USP), a Pontifícia Universidade Católica de São Paulo (PUC-SP) e a Fundação Getulio Vargas (FGV), instituições tradicionais e reconhecidas nacional e internacionalmente. $A$ participação dessas universidades na Rede Nossa São Paulo será retomada com mais profundidade adiante. Cabe destacar que o coordenador executivo e uma das principais lideranças da Rede Nossa São Paulo, Maurício Broinizi, apesar de professor universitário, não possui vínculo por meio da instituição.

\section{A Red Ciudadana Nuestra Córdoba}

A campanha para as eleições locais na cidade argentina de Córdoba, em 2007, sinalizou muitas promessas de campanha do então candidato a prefeito, reunidas na "Ata de Compromisso Público por uma Córdoba Sustentável," as quais, segundo os entrevistados, não foram cumpridas após sua eleição. O controle cidadão estava fragmentado em diversas instituições e organizações focadas em áreas específicas de ação sem um espaço comum de encontro (Gargantini et al., 2013). Era um cenário de desconfiança e pouca credibilidade da população em relação aos representantes.

Em abril de 2009, com a participação do Coordenador Executivo da Rede Nossa São Paulo, Maurício Broinizi, em uma reunião na Universidade Católica de Córdoba (UCC), foram convidados a Associação Civil Ágora, representantes do terceiro setor, universidades e câmaras empresariais de Córdoba, com a intenção de avaliar a possibilidade de desenvolver uma experiência semelhante à do Brasil. A partir desse encontro, afirmou-se a ideia de formar a Red Ciudadana 
Nuestra Córdoba.

O primeiro grupo promotor era composto por: Universidade Nacional de Córdoba (UNC), Universidade Católica de Córdoba (UCC), diário local La Voz del Interior, Fundação Avina, Associação Civil Ágora, Fundação Arcor, ONG Coletivo Ciudadano, Instituto Argentino de Responsabilidade Social Empresarial, ONG Wachay e Conselho Profissional de Ciências Econômicas (Gargantini et al., 2013). A partir de 2009, esse grupo ampliou-se para 80 membros, entre pessoas e organizações, que construíram a base do movimento.

Em 2010, apresentou-se a iniciativa ao público como um espaço plural, apartidário e autônomo em relação aos governos em todos os níveis, que propõe impulsionar uma cidade mais justa, democrática e sustentável (Gargantini et al., 2013; Red Ciudadana Nuestra Córdoba [RCNC], 2015).

A apresentação da rede foi realizada no dia 12 de maio de 2010, no auditório Diego Torres, da UCC. Encontravam-se ali o então Reitor da UCC, Rafael Velasco, o diretor do diário La Voz del Interior, Carlos Jornet, o representante da UNC, Carlos Lucca, Marcela Mondino, da Fundação Avina, e Pamela Cáceres, que fazia parte da Fundação Ágora e era então coordenadora executiva da Red Ciudadana Nuestra Córdoba. A ideia da iniciativa era reconhecer e instalar, na opinião pública e na agenda do Estado, os problemas que constituem obstáculos estruturais na busca por uma cidade melhor, mais justa, democrática e sustentável (Gargantini et al., 2013; RCNC, 2015).

Em 2011, a Red Ciudadana Nuestra Córdoba deu o primeiro grande passo para alcançar seus objetivos. Foi aprovada, por unanimidade, a proposta do Plano de Metas do Governo, principal projeto da rede, pelo qual o prefeito deve apresentar suas metas de gestão em 120 dias após assumir o cargo.

Quanto à constituição da Red Ciudadana Nuestra Córdoba, ela contava, em 2015, com 10 GTs, um Grupo Coordenador e uma Coordenação Executiva. Os GTs constroem informações sobre a cidade e a traduzem por meio de indicadores, informes e pesquisas que buscam gerar evidências sobre aspectos problemáticos que são obstáculos ao exercício do direito da cidade (RCNC, 2015). Os GTs possuem autonomia relativa dentro da rede, devendo seguir a Carta de Princípios e Propósitos Comuns (RCNC, 2015).

O Grupo Coordenador é constituído por cinco membros representantes de organizações integrantes da rede e exerce a representação institucional, velando pelo cumprimento da Carta de Princípios e Propósitos Comuns e pela coerência de estratégias e ações da rede. A equipe de Coordenação Executiva implementa estratégias e ações definidas pelo Grupo Coordenador.

Em 2015, a Red Ciudadana Nuestra Córdoba constitui-se como espaço apartidário do qual participam cerca de 200 cidadãos, ligados a aproximadamente 60 organizações, distribuídas conforme o Gráfico 2, a seguir: empresas locais $(3,3 \%)$, organizações da sociedade civil do meio empresarial (10\%), organizações da sociedade civil de base $(8,3 \%)$, organizações profissionais (35\%), universidades e centros de investigação (35\%), mídia (3,3\%), organizações internacionais $(1,6 \%)$, além de outras de menor participação. 
Gráfico 2. Distribuição dos integrantes da Red Ciudadana Nuestra Córdoba por setor

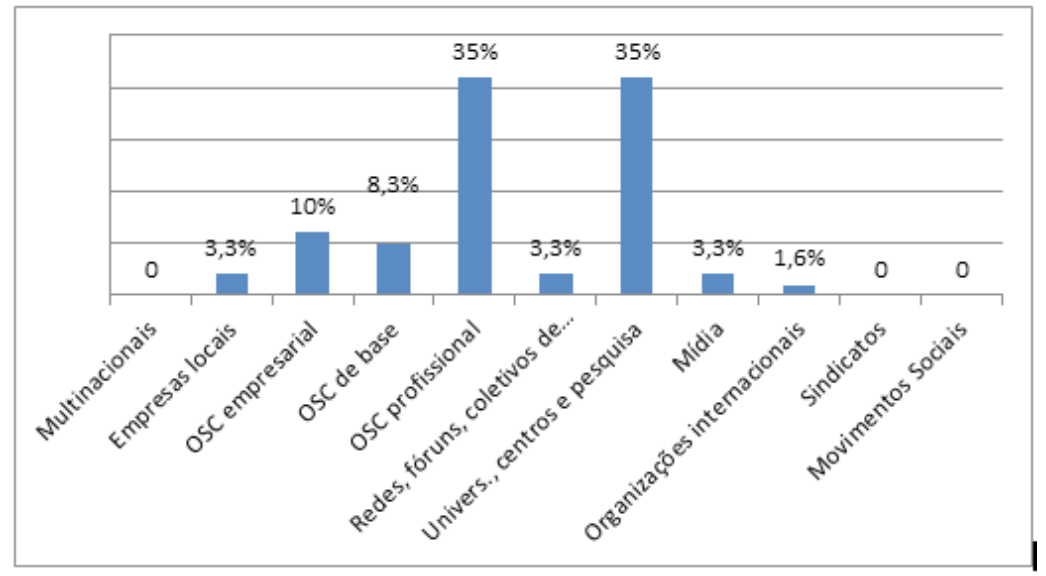

Fonte: Baseado de Red Ciudadana Nuestra Córdoba (2015).

A mídia é importante peça na divulgação de pesquisas e indicadores sobre a cidade e ações promovidas pela Red Ciudadana Nuestra Córdoba, fomentando a participação popular a partir da divulgação de informações. Cabe destaque ao diário La Voz del Interior, membro do grupo promotor da Red Ciudadana Nuestra Córdoba desde seu início e participante ativo desde então.

Outra organização fundamental para a constituição da rede desde seu início é a Fundação Avina, que gera e apoia processos colaborativos que buscam a melhoria na qualidade dos vínculos entre empreendedores, empresas, organizações da sociedade civil, setor acadêmico e instituições governamentais. A fundação é um importante catalisador de informações sobre ações da Red Ciudadana Nuestra Córdoba e outras da América Latina, apoiando-as e fomentando suas iniciativas.

Desde a fundação da rede, as universidades, especialmente a Nacional e a Católica, são membros permanentes do Grupo Coordenador e atuam intensivamente em várias frentes. Há, também, participação de outras universidades, como a Universidade Tecnológica Nacional, em algumas atividades.

Rafael Velasco, Reitor da UCC quando da criação da Red Ciudadana Nuestra Córdoba, em entrevista, reflete acerca de sua gestão diante da realidade da cidade de Córdoba. Para ele, o papel social refere-se à habilidade e efetividade de uma universidade responder às necessidades de transformações da sociedade em que está imersa. Para tanto, as funções de docência, investigação, projeção social e gestão interna devem estar alinhadas com a promoção da justiça, da solidariedade e da igualdade social, mediante a construção de respostas exitosas. Sobre os objetivos de sua gestão na universidade, Velasco diz que visava a produção de conhecimento com impacto social, e seus esforços sempre estiveram voltados ao envolvimento da universidade em grandes debates públicos. Segundo ele, o papel das universidades, como produtoras de conhecimento, é influir em benefício da sociedade. 
Nesse sentido, Velasco percebeu que as iniciativas que vinham surgindo em outras cidades latino-americanas, aliadas a elementos do contexto em Córdoba, faziam da criação da Red Ciudadana Nuestra Córdoba uma boa oportunidade para a universidade, naquele momento, na relação com a cidade. Isso porque essa relação teria um potencial de transformação na atuação da própria universidade, da Red Ciudadana Nuestra Cordoba e na influência de ambas no contexto local.

\section{RELAÇÃO ENTRE UNIVERSIDADES E AS REDES}

Retomando o objetivo de identificar os diferentes papéis que a universidade pode desempenhar quando se envolve em iniciativas da sociedade civil voltadas a informação, cidadania e accountability social em cidades latino-americanas, analisam-se a seguir: i) os papéis exercidos pelas universidades nas redes Nossa São Paulo e Nuestra Cordoba; ii) possíveis razões que explicam as diferenças entre uma cidade e outra; e iii) efeitos da interação entre universidade e iniciativas na atuação da Rede Nossa São Paulo e da Red Ciudadana Nuestra Córdoba, nas universidades e nas cidades em que se situam.

Quanto aos papéis exercidos pelas universidades diante das iniciativas, verificam-se, nos dois casos, (i) o apoio institucional e (ii) o aporte de metodologias e conhecimentos especializados, contribuindo para a legitimidade dessas iniciativas e para a produção de informações sobre a cidade. Tais contribuições ocorrem de variadas maneiras e em diferentes graus de intensidade nas duas cidades, sendo mais evidentes, contínuas e institucionalizadas em Córdoba do que em
São Paulo. Além disso, em Córdoba, há (iii) contribuição financeira das universidades para a Red Ciudadana Nuestra Córdoba e (iv) envolvimento direto e continuado de reitores, professores e estudantes das universidades no grupo coordenador e em atividades da rede, desde seu início até os dias atuais. Projetos e ações relacionados à rede foram institucionalizados nas universidades, que passaram a incentivar, inclusive financeiramente, o desenvolvimento de pesquisas e outras ações relacionadas aos desafios da cidade.

Em Córdoba, a presença universitária contribui para a identidade e para a legitimidade da Red Ciudadana Nuestra Córdoba, uma vez que as universidades, que gozam de prestígio e confiabilidade na sociedade e entre os gestores públicos, foram promotoras de sua criação e integram o grupo coordenador. As universidades envolvidas desempenham papel não apenas técnico, mas também político, especialmente por meio de seus reitores, lideranças historicamente reconhecidas na cidade e empenhadas pessoalmente na constituição da Rede Ciudadana Nuestra Córdoba. Além disso, Córdoba pode ser considerada uma cidade universitária, dada a relevância histórica e o número de instituições na cidade, e o volume de acadêmicos que vivem na mesma.

Já em São Paulo, as universidades não institucionalizaram projetos ou ações relativas à Rede Nossa São Paulo. A PUC-SP, a FGV e a USP, por exemplo, contribuem em atividades específicas, como consultoria acerca de metodologias aplicáveis à rede, por meio do envolvimento voluntário de pesquisadores e professores. Esse envolvimento direto ou indireto com ações promovidas pela Rede 
Nossa São Paulo dá-se a partir do interesse como cidadãos e como pesquisadores, já que as temáticas em torno das redes $\mathrm{e}$ suas relações são oportunidades de estudo e pesquisa no âmbito acadêmico. A própria constituição e atuação da Rede Nossa São Paulo é tema de pesquisas acadêmicas, entre elas as realizadas por Fiabane, Alves e Brelàz (2014) e Nascimento (2015).

Além disso, são criadas oportunidades de conexão de acadêmicos com a comunidade, como ocorre, por exemplo, em um curso de gestão social urbana, promovido pela FGV-EAESP em um bairro da Zona Sul de São Paulo, que surgiu a partir de conversas de acadêmicos com as lideranças locais. A Rede Nossa São Paulo recebe, ainda, contribuições como a do professor e pesquisador Ladislau Dowbor e do Núcleo de Estudos do Futuro (NEF), da PUC, que elaboraram a proposta do Guia Gestão Pública Sustentável (GPS), aplicado ao Programa Cidades Sustentáveis.

A não institucionalização de ações voltadas à Rede Nossa São Paulo nas universidades, não significa que não haja o exercício do papel social das universidades ou que elas não se envolvam em questões relativas à cidade. Muitas pesquisas, campanhas e debates promovidos pelas universidades, embora não ligadas diretamente à Rede Nossa São Paulo, guardam relação com temas trabalhados no âmbito da rede. A seguir, são citadas algumas dessas atividades, , que vão ao encontro das linhas de ação da Rede Nossa São Paulo, embora nem sempre ocorram de maneira conjunta e continuada:

- Escola Politécnica/Faculdade de En- genharia da USP, por meio do Programa Poli-Cidadã: além de estimular seus alunos no desenvolvimento de atividades de caráter social, vários trabalhos desenvolvidos pela Poli, especialmente relacionados à mobilidade urbana, contribuíram para o GT de mobilidade urbana da Rede Nossa São Paulo. A principal liderança do movimento, Oded Grajew, é um engenheiro e ex-aluno da escola. Em conjunto com o Programa Poli Cidadã, a Rede Nossa São Paulo buscou identificar pontos críticos na cidade e propor propostas de projetos.

- Núcleo de Estudos do Futuro (NEF), da PUC-SP: o professor Ladislau Dowbor foi convidado para dar suporte metodológico aos objetivos da rede e contribuir na implantação do Programa de Cidades Sustentáveis no Brasil, originando a ferramenta Guia GPS.

- Centro de Estudos em Sustentabilidade, GV-Ces, da FGV: trabalha os temas da economia de baixo carbono, indicadores de sustentabilidade, inovação, investimento responsável, políticas públicas, relações com as comunidades, sustentabilidade no consumo etc., os quais são acompanhados pela Rede Nossa São Paulo.

- Instituto Saúde e Sustentabilidade, ISS, da USP: especialmente por meio do professor Dr. Paulo Saldiva, foi realizada pesquisa sobre mobilidade urbana e impacto da poluição do ar na qualidade de vida. A Rede Nossa São Paulo aproximou-se em vários momentos do processo, pois realizava uma campanha para melhorar a qualidade do combustível.

- EAESP, da FGV: curso de gestão social urbana em um bairro da Zona Sul de São Paulo, o Jardim Ângela, em parceria com 
a Sociedade Santos Mártires e outras organizações que fazem parte da Rede Nossa São Paulo. A ideia surgiu a partir de conversas com as lideranças locais, especialmente com o Padre Jaime, uma liderança local presente na constituição da Rede Nossa São Paulo.

- Debate sobre a construção do Plano Municipal de Transporte de São Paulo realizado na PUC-SP durante a programação do Dia Mundial sem Carro, promovido pela Rede Nossa São Paulo.

- FGV e o movimento Chega de Acidentes: lançamento da Década de Ações para a Segurança Viária no Brasil - Marco Zero - para redução de acidentes no trânsito promovido pela Rede Nossa São Paulo.
No que concerne ao financiamento das iniciativas, conforme mostrado na Tabela 1, na Red Ciudadana Nuestra Córdoba, grande parte dos recursos provém das universidades. Em 2014, do total de recursos financeiros recebidos pela rede, $57 \%$ foram provenientes de duas universidades. Além disso, diversos outros recursos, de caráter institucional, econômico, científico e sociopolítico, são aportados direta ou indiretamente pelas universidades na Red Ciudadana Nuestra Córdoba. Já na Rede Nossa São Paulo, conforme demonstrado na Tabela 2, a maior parte dos recursos financeiros provém de fundações e empresas, enquanto as universidades sequer figuram entre os principais financiadores.

Tabela 1. Origem dos recursos financeiros da Red Ciudadana Nuestra Córdoba

\begin{tabular}{|c|c|}
\hline Aportes 2014 & Monto \\
\hline Fondo UNC & $\$ 101.200$ \\
\hline Fondo UCC & $\$ 81.000$ \\
\hline Fondo Arcor & $\$ 78.000$ \\
\hline Fondo AVINA (Jhonson) & $\$ 19.500$ \\
\hline Fondo Avina Proyecto Reciclaje & $\$ 20.729$ \\
\hline Fondo AVINA Aporte IV Foro & $\$ 4.000$ \\
\hline Fondo IBM & $\$ 9.000$ \\
\hline Fondo Telecom & $\$ 7.000$ \\
\hline TOTAL & $\$ 320.429$ \\
\hline
\end{tabular}

Fonte: Red Ciudadana Nuestra Córdoba (2015). 
Tabela 2. Origem dos recursos financeiros da Rede Nossa São Paulo

\begin{tabular}{|c|c|}
\hline & JANEIRO A DEZEMBRO DE 2014 \\
\hline CONTAS DE RESULTADO & $-R \$ 293.054,25$ \\
\hline TOTAL DE RECEITAS (Soma dos itens I a IX) & $-\mathrm{R} \$ 3.611 .819,59$ \\
\hline 1. CONTRIBUICAO DE ASSOCIADO ORGANIZACIONAL & $-780.480,00$ \\
\hline II. RECURSOS FUNDAÇÃO FORD & $-203.062,52$ \\
\hline III. RECURSOS BID & $-80.228,00$ \\
\hline IV. CAF & $-111.600,00$ \\
\hline V. RECURSOS FUNDAÇ̃̃O AVINA & $-578.659,72$ \\
\hline VI. RECURSOS INSTITUTO ARAPYAU & $-1.333 .333,30$ \\
\hline VII. RECURSOS INSTITUTO ETHOS & $-50.000,00$ \\
\hline VIII. OUTRAS RECEITAS & $-2.545,00$ \\
\hline IX. OPEN SOCIETY & $-157.010,00$ \\
\hline X. PATROCINIO A CONFERENCIA & $-250.000,00$ \\
\hline XI. INSTITUTO B. E J. LAFER & $-40.000,00$ \\
\hline XII. PORTICUS & $-18.406,87$ \\
\hline XIII. RECEITAS COM GRATUIDADES & $-6.494,18$ \\
\hline TOTAL DE DESPESAS (Soma dos itens I, II e III) & R\$ $3.583 .135,05$ \\
\hline
\end{tabular}

Fonte: Rede Nossa São Paulo (2015).

As razões que explicam as diferenças na relação entre universidades e iniciativas em cada cidade estão possivelmente relacionadas (i) ao contexto histórico, político e institucional da cidade; (ii) às lideranças que atuaram na constituição da iniciativa; (iii) à visão das universidades quanto ao envolvimento em iniciativa voltada a informação, cidadania e accountability na cidade.

Córdoba poderia ser definida, genericamente, como cidade universitária, enquanto São Paulo poderia receber o título genérico de cidade industrial. Esses rótulos não dizem tudo sobre essas cidades, mas apontam para uma característica central da identidade de cada uma delas. Na cidade de São Paulo, há predominância industrial e empresarial como motores do desenvolvimento, embora a cidade também se destaque como pólo acadêmico e cultural. Já o desenvolvimento da cidade de Córdoba está atrelado ao papel histórico das universidades e sua influência política, técnica e cultural, embora também haja destaques do meio empresarial.

Essa influência de características históricas e sociopolíticas da cidade na estrutura e nas ações das iniciativas que compõem a RLCTJDS foi observada em outros estudos, como o realizado por Dahmer (2014) nas cidades brasileiras de Florianópolis, Ilhabela e llhéus.

Além disso, a constituição da Rede Ciudadana Nuestra Córdoba e da Rede Nossa São Paulo está intimamente ligada à atuação de lideranças que desempenham um papel-chave na sociedade e representam o perfil característico de cada cidade. Em Córdoba, um dos principais idealizadores da iniciativa foi o ex-reitor da Universidade Católica, Rafael Velasco, que valoriza o envolvimento da universidade em questões sociais. Já em São Paulo, evidenciam-se lideranças ligadas ao desenvolvimento econômico e religioso, notadamente Oded Grajew, empresário reconhecido por sua capacidade articuladora, política e empreendedora em 
temas coletivos, e os padres Jaime Crowe e Ticão (Fiabane, Alves, \& Brelàz, 2014).

Em Córdoba, o interesse de participação institucional das universidades na Red Ciudadana Nuestra Córdoba partiu de gestores e pesquisadores universitários. Já em São Paulo, a Rede Nossa São Paulo, na sua formação, buscou apoio de instituições universitárias, mas não houve envolvimento institucional e de gestores universitários na iniciativa. Ao longo do tempo, o que ocorreu foi a atuação voluntária e pontual de pesquisadores em interação com a rede.

A Red Ciudadana Nuestra Córdoba constituiu uma oportunidade ímpar para as universidades atualizarem sua maneira de exercer relevância na vida cidade, na opinião de diversos entrevistados. Elas sempre foram relevantes, desde a origem da cidade, e já em 1918 foram precursoras de transformações da universidade na América Latina, a partir do Movimento de Córdoba. Diante dos desafios e oportunidades do tempo atual, as instituições acadêmicas locais viram na articulação cidadã em rede um caminho para exercitar a interdisciplinaridade, a conexão ensino-pesquisa-extensão, e o exercício do seu papel político e científico. Fazem-no mobilizando suas próprias capacidades e recursos - lideranças, professores, pesquisadores, estudantes, institucionais, financeiros, programas, projetos - e contribuindo para articular diversos segmentos da sociedade local.

Um desafio apontado pelos entrevistados em ambas as cidades, especialmente aqueles ligados às universidades, é justamente o relativo à abertura da universidade às demandas sociais. Segundo os entrevistados, ainda há resistência da comunidade acadêmica para dar respostas a atores de fora do meio acadêmico - cidadãos, empresas, movimentos sociais, os quais representam outros saberes que podem ser articuladores com o saber científico.

A articulação de diferentes saberes é visível tanto no âmbito da Nuestra Córdoba quanto da Nossa São Paulo. Os saberes científicos combinam-se com saberes técnicos e políticos presentes em diversos grupos, como empresas de pesquisa, grupos de mídia, organizações da sociedade civil, movimentos sociais, lideranças comunitárias e especialistas voluntários. Essa ecologia de saberes, usando a expressão de Santos (2010), inclui as universidades, mas não depende unicamente delas, sobretudo no caso de São Paulo. As características da cidade de Córdoba tornam mais visível a atuação das universidades. Portanto, talvez haja mais valorização do conhecimento universitário na Rede Ciudadana Nuestra Córdoba. Já em São Paulo, embora as universidades e o conhecimento científico sejam relevantes para a produção de conhecimento sobre a cidade, uma grande pluralidade de atores é diretamente envolvida na produção de conhecimentos importantes para a Rede Nossa São Paulo.

O Quadro 1, a seguir, sintetiza as características da Rede Ciudadana Nuestra Córdoba e da Rede Nossa São Paulo considerando o contexto em que estão inseridas, sua constituição, lideranças e produção de conhecimento. 
O PAPEL DA UNIVERSIDADE EM INICIATIVAS VOLTADAS À INFORMAÇ̃̃o, CIDADANIA E ACCOUNTABILITY EM CÓRDOBA E SÃo PAULO

Quadro 1 Síntese de características da Red Ciudadana Nuestra Córdoba e da Rede Nossa São Paulo

\begin{tabular}{|l|l|l|}
\hline & Nuestra Córdoba & Nossa São Paulo \\
\hline $\begin{array}{l}\text { Característica da cida- } \\
\text { de }\end{array}$ & Universitária & Industrial \\
\hline $\begin{array}{l}\text { Constituição da inicia- } \\
\text { tiva }\end{array}$ & $\begin{array}{l}\text { A partir das universidades, } \\
\text { articulando diversos seg- } \\
\text { mentos }\end{array}$ & $\begin{array}{l}\text { A partir de pessoas do meio } \\
\text { empresarial, articulando diver- } \\
\text { sos segmentos }\end{array}$ \\
\hline Lideranças & Universitárias; política & Empresariais; executiva \\
\hline $\begin{array}{l}\text { Protagonismo na pro- } \\
\text { dução de conhecimen- } \\
\text { to }\end{array}$ & Universidade; mídia & $\begin{array}{l}\text { Empresas; institutos de pes- } \\
\text { quisa; mídia; especialistas }\end{array}$ \\
\hline $\begin{array}{l}\text { Principais financiado- } \\
\text { res }\end{array}$ & Universidades, fundações & Empresas, fundações \\
\hline
\end{tabular}

Finalmente, com base nos casos de Córdoba e São Paulo, sintetizam-se alguns efeitos da interação entre universidade e iniciativas voltadas à informação, cidadania e accountability social nas cidades. Nas duas cidades, os entrevistados observam a importância de a universidade abrir suas portas e reconhecer outros saberes existentes na sociedade para alcançar mudanças na própria instituição e na realidade das cidades. Considerando a cidade como construção social coletiva e dinâmica, a articulação de diferentes saberes em cada cidade e as conexões entre elas geram efeitos em três âmbitos:

I. Novos espaços institucionalizados de articulação de saberes e formas de produção de conhecimentos na cidade, a exemplo dos grupos de trabalho constituintes das iniciativas, dos fóruns e campanhas promovidas, e das pesquisas de percepção cidadã, que geram processos e produtos, como dados sobre a cidade, indicadores, propostas de políticas, programas e ações. As iniciativas da RLCTJDS constituem o que Toro (2001) considerou como espaços potenciais de socialização orientados a propósitos coletivos, nos quais novos atores e canais de produção e democratização de conhecimento sobre a cidade podem emergir e ganhar reconhecimento e legitimidade (Delanty, 2001), pois ampliam a diversidade de atores na construção social da realidade. Admitindo-se que conhecimento é poder, a produção e articulação de informações e conhecimentos diversos - científico, popular, militante e do senso comum - gera e distribui poder entre variados grupos na sociedade, fortalecendo-os para monitorar, cobrar, propor e agir na governança da cidade. Além das articulações em cada cidade, tanto a Nossa São Paulo como a Nuestra Córdoba dialogam entre si e compartilham conhecimentos e metodologias com outras iniciativas que integram a RLCTJDS, contribuindo técnica e politicamente para fortalecer a ação em cada cidade

II. Mudanças em instituições tradicionais como a universidade, o que é mais claramente visível no caso de Córdoba. Como 
exemplo, a Universidade Católica institucionalizou ações voltadas a Red Ciudadana Nuestra Córdoba, gerando mudanças em suas políticas de pesquisa e extensão. Conforme declaração dos entrevistados, especialmente gestores da rede e das universidades, bem como registros em documentos, como boletins e editais, observa-se avanços em interdisciplinaridade, em trabaIhos envolvendo diferentes áreas, voltados a problemas da cidade, como o tratamento do lixo, por exemplo. Entretanto, mesmo havendo mudanças institucionais, as universidades conservam aspectos da tradição, e há resistências a mudanças em relação ao seu engajamento com o contexto das cidades. Em São Paulo, o fato de as universidades não estarem envolvidas de modo institucionalizado e contínuo com a Rede Nossa São Paulo não significa que não estejam se transformando, por outros meios, em conexão com outras iniciativas na cidade e no país, em função de elementos do contexto contemporâneo. Isso porque estão submetidas a novas formas de produção de saberes, a exemplo do curso de gestão social urbana promovido pela FGV a partir da interação e demandas levantadas pela comunidade e pelas lideranças locais ou, ainda, quando participam de fóruns e debates que discutem desafios e propostas para a cidade. Estão submetidas também aos desafios na cidade, da cidadania, da solução de problemas ambientais, de serviços, mobilidade etc. A Rede Nossa São Paulo, por alguma razão, não parece ser um canal preferencial para que importantes universidades se envolvam com os problemas da cidade. Porém, isso não significa que não haja envolvimento com essas questões, ou que elas não o façam pontualmente com a Rede Nossa São Paulo. Pesquisas e projetos individuais, por meio de pessoas isoladas, porém vinculadas a instituições universitárias, são desenvolvidas e geram resultados para ambas.

III. Ampliação e reconfiguração de espaços institucionais de articulação entre governos e cidadãos, afetando a governança na cidade e os modos de coordenação social na cidade - as tradições, processos e instituições relativos ao exercício do poder na cidade. Mesmo que não se trate de avaliar impactos, tampouco de atribuir as mudanças em governança nas cidades apenas a essas iniciativas, há evidências de que isso ocorre. Por exemplo, uma das principais conquistas em ambas as cidades, e que se tornou exemplo para as demais, foi a aprovação da Lei do Plano de Metas, que busca garantir o compromisso dos representantes com as questões da cidade (Cáceres, 2014). Outros exemplos são os painéis com gestores públicos e especialistas em temas desafiadores para a cidade, com participação direta ou indireta das universidades.

Criam-se, portanto, novas formas de accountability na cidade em função da ação dessas iniciativas voltadas ao engajamento dos cidadãos na solução dos problemas. Lançam-se novas formas de articulação entre democracia representativa e participativa, influenciando a concepção de políticas públicas - o que não significa homogeneidade ou ausência de conflitos.

A universidade, como parte dessas iniciativas, contribui para esse processo nas cidades e também se transforma, a depender da intensidade e da natureza de seu envolvimento e interação com outros atores em cada local. 


\section{CONSIDERAÇÕES FINAIS}

O objetivo do trabalho foi identificar os diferentes papéis que a universidade pode desempenhar quando se envolve em iniciativas da sociedade civil voltadas a informação, cidadania e accountability social em cidades latino-americanas, particularmente nas iniciativas da Rede Nossa São Paulo e da Red Ciudadana Nuestra Córdoba. Tais iniciativas, assim como outras integrantes da RLCTJDS, visam a produção e disseminação de informações, de participação cidadã e de accountability social nas cidades. Buscou-se observar os diferentes papéis, as razões que os explicam e os efeitos da interação entre universidade e iniciativas na atuação de ambas e nas suas cidades. Os efeitos dessa interação na atuação de ambas as iniciativas e nas suas cidades foram expostos em três aspectos principais: (I) criação de novos espaços institucionalizados de articulação de saberes e formas de produção de conhecimentos na cidade; (II) mudanças em instituições tradicionais como a universidade; (III) ampliação e reconfiguração de espaços institucionais de articulação entre governos e cidadãos.

O protagonismo das universidades em cada iniciativa e em cada contexto é variado. Os movimentos por cidades são uma oportunidade de engajamento e articulação entre teoria e prática e de aproximação das universidades de sua realidade. Tanto pela contemporaneidade dos temas associados aos antigos e novos desafios vivenciados nas cidades latino-americanas quanto pelas inovações que essas iniciativas vêm experimentando para produzir informações, mobilizar a cidadania, demandar e produzir accountability, monitorar a qualidade de vida e democratizar a governança nas cidades.

Quanto às limitações do trabalho, alguns pontos merecem destaque. Primeiramente, o número de entrevistados em cada cidade foi diferente. Isso deve-se, especialmente, ao fato de, em Córdoba, as principais instituições envolvidas, como dito, serem as universidades, e, portanto, houve um interesse especial pelo tema por parte dos representantes. Já em São Paulo, encontrou-se dificuldade de contato com representantes ligados às universidades, ficando limitado a poucos deles. Outra limitação foi o número de casos estudados, dadas as limitações de tempo e recursos. Diferentes casos podem vir a ser estudados, abordando-se outros possíveis papéis desempenhados pelas universidades em diferentes contextos. Podem, ainda, ser identificadas razões adicionais para o envolvimento de universidades nessas iniciativas e novos efeitos gerados.

Outras iniciativas da RLCTJDS, em diferentes portes de cidade, regiões e países, podem ser abordadas em outras oportunidades, investigando-se detalhes da sua relação com universidades, e seus efeitos. Outras abordagens teóricas também tendem a enriquecer a análise dos casos. Há possibilidade de uma abordagem semiótica dessa relação, ampliando a visão dos possíveis papéis desempenhados pelas organizações envolvidas. Pode-se observar, por exemplo, a disposição das universidades em determinados espaços urbanos, instaladas de modo acessível ou não, integradas ou não à cidade. Algo que foi observado nos casos de Córdoba e São Paulo, porém não chegou a ser analisado. Constituem, assim, oportunidade para pesquisas futuras, com novos aportes teóricos. 


\section{REFERÊNCIAS}

Abrucio, F. L., \& Loureiro, M. R. (2005). Finanças públicas, democracia e accountability. In P. R. Arvate, \& C. Biderman C. (Orgs.), Economia do setor público no Brasil (pp. 75102). Rio de Janeiro, RJ: Elsevier/Campus.

Bernheim, C. T., \& Chauí, M.S. (2008). Desafios da universidade na sociedade do conhecimento. Brasília, DF: Unesco.

Cáceres, P. (2014). Planes de metas como innovaciones em los processos de rendición de cuentas en el nível local. Experiencias en el marco de la Red Latino Americana por Ciudades Justas, Democráticas y Sustentables. Córdoba, Argentina.

Chauí, M. (2003). A universidade pública sob nova perspectiva. Revista Brasileira de Educação, 24, 5-15. doi:10.1590/S141324782003000300002

Dahmer, J. (2014). Ação coletiva, governança democrática e accountability social na construção de cidades sustentáveis: Os casos de Florianópolis, Ilhabela e llhéus (Dissertação de Mestrado, Universidade do Estado de Santa Catarina, Florianópolis).

Delanty, G. (2001). Challenging knowledge. The university in the knowledge society. Buckingham: SRHE and Open Society Press.

Echavarría, C. (2014). Dimensiones transformadoras de la participación ciudadana. $\mathrm{X}$ Cohorte del Programa de Maestría en Planificación del Desarrollo Regional. Programa de Postgrado de la Escuela de Ciencias
Sociales, Universidad de Oriente, Nucleo Sucre, Venezuela.

Fiabane, D. F., Alves, M. A., \& Brelàz, G. (2014). Social accountability as an innovative frame in civic action: The case of Rede Nossa São Paulo. Voluntas, 25, 818-838.

Gargantini, D. M., D’Amico, D., Martiarena, M., \& Peralta, J. (2013). Indicadores de control ciudadano para el goce efectivo del derecho a la ciudad en términos de desarrollo urbano para la ciudad de Córdoba (Argentina). Cuadernos de Vivienda y Urbanismo, Córdoba, Argentina.

Gómez, J. M., \& Delgado, A. C. (2011). Accountability social e o problema da corrupção na Indía, Brasil e África do Sul. Núcleo de Análises de Economia e Política dos Países BRICS. Centro de Estudos e Pesquisa BRICS.

Jiménez, M. C. (2012). La importancia del accountability social para la consolidación de la democracia en América Latina: Estrategia y seguridad. Revista de Relaciones Internacionales, 7(2), 97-130.

Nascimento, I. C. R. (2015). Governança democrática de cidades e accountability social: Análise do perfil das organizações da sociedade civil participantes da Rede Nossa São Paulo. Relatório Final PIBIC. São Paulo, SP: Universidade de São Paulo.

O'Donnell, G. (1998). Accountability horizontal e novas poliarquias. Revista de Cultura e Política, 44, 27-54. doi:10.1590/S010264451998000200003

Quinõnes, A. H. (2011). Análisis y estudio de 
experiencias de accountability social en América Latina. CIDER - Centro de Estudios Interdisciplinarios Sobre el Desarrollo. (Informe final de investigación - Convenio de cooperación entre Fundación Corona y Universidad de Los Andes, apoyo Fundación Corona y Fundación Avina - Red Latinoamericana por Ciudades Justas y Sustentables). Bogotá: CIDER.

Quinõnes, A. H., \& Cuadros, D. (2014). Iniciativas de transparência y accountability en America Latina: Naturaleza, tipológía e incidência en la democracia y el desarollo. In D. Pinheiro, D. Melo, \& J. Costa (Orgs.), Democracia: Desafios, oportunidades e tendências (pp. 226-270). Florianópolis, SC: Imaginar o Brasil.

Red Ciudadana Nuestra Cordoba. (2015). Institucional. Cordoba, Argentina: RCNC. Recuperado de http://www.nuestracordoba. org.ar/

Rede Nossa São Paulo. (2015). Institucional. São Paulo, SP: RNSP, 2015. Recuperado de http://www.nossasaopaulo.org.br/institucional

Santos, B. S. (2010). Para além do pensamento abissal: Das linhas globais a uma ecologia de saberes. In Santos, B. S., Meneses, M. P (Orgs). Epistemologias do Sul (pp. 31-83). São Paulo, SP: Cortez.

Santos, B. S. (2011). A universidade no século XXI: Para uma reforma democrática e emancipatória da universidade. São Paulo, SP: Cortez.

Schommer, P. C., \& Boullosa, R. F. (2010). Com quantas andorinhas se faz um verão? Práticas, relações e fronteiras. In $P$. C. Schommer, \& I. G. Santos, Aprender se aprende aprendendo: Construção de saberes entre universidade e sociedade (pp. 1741). Salvador, BA: CIAGS, FAPESB, SECTI, CNPq.

Toro, J. B. (2001). El saber social y los contextos de aprendizaje. IV Seminario Internacional de Educación, Belo Horizonte, MG. Recuperado de http://www.iberopuebla.edu. $\mathrm{mx} / \mathrm{micrositios/ceamope/docs/latapi/saber-}$ social.pdf

Vallaeys, F. (2004). Enseñar la ética y el desarrollo en la universidad en la era planetaria (Maestría en gerencia social de la Pontificia Universidad Católica del Perú, Lima, Perú). 